\title{
O despertar da rivalidade: Os debates entre o Barão do Rio Branco e Estanislao Zeballos por meio da imprensa (1904-1908)
}

\author{
Renato Cesar Santejo Saiani ${ }^{1}$ \\ Camila Bueno Grejo ${ }^{2}$
}

\begin{abstract}
Resumo: As relações entre Brasil e Argentina sofreram inúmeras mudanças ao longo do século XIX e início do XX. Durante o período Rio Branco, 1902-1912, tais vínculos foram marcados por etapas de concórdia, entremeadas por períodos de rivalidade acentuada. O projeto de rearmamento naval brasileiro, aprovado em 1904 e modificado em 1906, foi catalisador de um dos momentos mais delicados das relações políticas entre os dois países. A nomeação de Estanislao Zeballos para o Ministerio de Relaciones Exteriores y Culto, em 1906, exacerbou a situação. Foram intensas as discussões entre os ministros, os representantes diplomáticos, observando-se uma grande exaltação da opinião pública. Essa ebulição foi incitada, em grande medida, pela utilização que Rio Branco e Zeballos faziam da imprensa para movimentar o cenário político da época. Este trabalho tem por objetivo analisar os artigos, publicados tanto na imprensa brasileira como na argentina, no intuito de compreender como se desenrolou esse debate e qual sua influência na crise armamentista que abalou as relações políticas entre as duas nações.
\end{abstract}

Palavras-chave: Barão do Rio Branco; Estanislao Zeballos; imprensa, política externa.

\section{The awakening of rivalry: Debates between the Baron of Rio Branco and Estanislao Zeballos through the press (1904-1908)}

\begin{abstract}
Relations between Brazil and Argentina have undergone numerous changes throughout the nineteenth century and early twentieth. During the Rio Branco period, 1902-1912, such ties were marked by steps of concord, interspersed with periods of sharp rivalry. The Brazilian naval rearmament project, approved in 1904 and modified in 1906, was the catalyst for one of the most delicate moments of political relations between the two countries. The appointment of Estanislao Zeballos for the Ministerio de Relaciones Exteriores y Culto in 1906, exacerbated, the situation. Discussions between ministers and diplomatic representatives were intense, observing a great exaltation of public opinion. This boiling policy was prompted largely by the use that Rio Branco and Zeballos made of the press to move the political landscape of the time. This paper aims to analyze the articles published in the Brazilian press as much as in Argentina in order

\footnotetext{
${ }^{1}$ Doutorando em História no Programa de Pós-Graduação da Faculdade de Ciências e Letras, UNESP Universidade Estadual Paulista - Campus de Assis. Pesquisa em andamento: Política, território e identidade nos artigos de imprensa do Barão do Rio Branco (1889-1912). Agência financiadora: CAPES. E-mail: nasai85@yahoo.com.br.

${ }^{2}$ Doutora em História pela Universidade Estadual Paulista - UNESP/Assis E-mail: camila_grejo@hotmail.com.
}

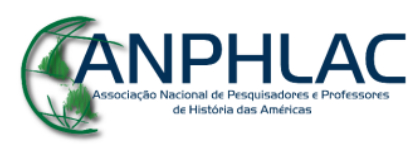

Revista Eletrônica da ANPHLAC, ISSN 1679-1061, №. 22, p. 182-201, Jan./Jun., 2017.

http://revista.anphlac.org.br 
to understand how the debate unfolded and what their influence in the Arms crisis that shook the political relations between the two nations.

Keywords: Baron of Rio Branco; Estanislao Zeballos; press; foreign policy.

\section{Artigo recebido em: $31 / 10 / 2016$}

\section{Artigo aprovado para publicação em: 19/03/2017}

No período compreendido entre os anos finais do século XIX e os iniciais do XX as relações entre Brasil e Argentina foram marcadas tradicionalmente por uma série de oscilações que ora pendiam para a cordialidade, ora para uma aguda rivalidade. De acordo com José Paradiso (2005, p. 52), os países mantinham uma atenção recíproca prioritária que não se baseava apenas em desavenças fronteiriças, mas também em uma atitude preventiva ligada a questões de equilíbrio regional, alimentadas por um legado histórico herdado da antiga rivalidade luso-espanhola.

Boris Fausto e Fernando Devoto (2004, p. 227) caracterizam o campo das relações internacionais dos dois países como uma via dupla com ligações entre si, formada, de uma parte, pelo papel desempenhado no mundo e, de outra, pela posição de cada um deles no continente americano, especialmente no Cone Sul. Para os autores, Brasil e Argentina apresentavam muitas semelhanças na posição ocupada no contexto internacional, pois eram países periféricos com escassas possibilidades de encontrar um espaço ao lado das potências. A Argentina estava ligada ao capital inglês na área do comércio exterior, dos investimentos e dos empréstimos internacionais, enquanto o Brasil, nas últimas décadas do Império, realizava uma política de gradativa aproximação com os Estados Unidos, país que demonstrava, cada vez mais, seu interesse em desempenhar um papel hegemônico na América e ter maior presença no cenário mundial.

O Brasil iniciava um processo de estabilização frente às turbulências da primeira década republicana, marcada por desastres políticos e econômicos, tais como o Encilhamento, os golpes militares, as lutas da época de Floriano, os degolamentos e fuzilamentos sumários na Revolução Federalista, a Revolta da Armada e a Rebelião de Canudos. Portanto, precisava estabelecer políticas econômicas mais sólidas e que

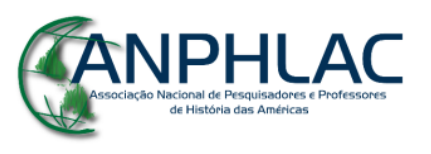


proporcionassem o aumento nos preços do café. Em relação à situação externa, o Brasil também buscava ajustar suas intenções e julgava fundamental o estreitamento dos laços com os Estados Unidos tanto pelo aspecto econômico, já que se tratava do principal comprador do café brasileiro, como também para a efetivação de suas aspirações políticas regionais e mundiais. Nesse sentido, podemos afirmar que, no início do período republicano, a política externa brasileira estava fortemente norteada pelo ideal americanista, o que levou a exageros na cortesia com o governo argentino, enquanto este, segundo a perspectiva de Amado Cervo (1995, p. 8), "festejara a República com emoção, mas não abriria mão de seus interesses e os realizaria a expensas daqueles de seu vizinho, caso este o permitisse por descuido."

A Argentina, por sua vez, seguia na corrente oposta. A estabilidade política conquistada desde a consolidação do Estado nacional conjugada ao incentivo da entrada de capital estrangeiro, da expansão da malha ferroviária e do maciço fluxo migratório que alavancou os diferentes setores produtivos, levaram o país a um espantoso crescimento a partir da década de 1860, comparável apenas ao dos Estados Unidos. Tornou-se o principal exportador mundial de grãos e sobrepusera-se à exportação de carne dos Estados Unidos para a Grã-Bretanha (BUENO, 2003, p. 169). O crescimento econômico experimentado no final do século XIX e mantido durante a primeira década do XX inspirou seus dirigentes a desempenhar uma missão civilizadora na América Latina, demarcando sua hegemonia sobre a região. As atenções fora do continente, por sua vez, estavam voltadas para a Europa, sobretudo direcionadas à Grã-Bretanha, e era reativa às pretensões norte-americanas de aumento de influência sobre o hemisfério baseadas na égide do pan-americanismo ${ }^{3}$.

A relação de trocas comerciais entre o Brasil e a Argentina era estável, expressiva e de caráter complementar, com saldos largamente favoráveis ao país platino que dominava o mercado brasileiro de gêneros alimentícios, sobretudo trigo em grão e farinha. A Argentina, por outro lado, não figurava entre as grandes importadoras dos produtos brasileiros, dos quais absorvia café e mate, com altas taxas alfandegárias, e, em menor medida, açúcar e cacau. Poucos foram os momentos em que essa balança

\footnotetext{
${ }^{3}$ Para maiores informações sobre o tema, ver MORGENFELD, Leandro. Vecinos en conflicto: Argentina y Estados Unidos en las conferencias panamericanas (1880-1955). Buenos Aires: Ediciones Continente, 2011.
}

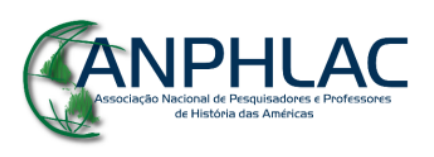


sofreu abalos. Contudo, contrariando a lógica do relacionamento econômico, as relações políticas ainda se mantinham instáveis, com períodos de cordialidade entremeados por outros de rivalidade acirrada.

Neste artigo, buscaremos analisar como se desenvolveram tais relações em um período agudo de rivalidades, manifestadas a partir de uma crise diplomática devido à compra de armamentos navais pelo Brasil e à suposta ameaça de um conflito bélico, conforme sustentava a chancelaria argentina.

\section{A nova república americana}

A República brasileira, proclamada em 1889, contou com o rápido reconhecimento por parte do país vizinho que, àquela época, tinha Estanislao Zeballos à frente da pasta do Exterior. Os governos argentino e brasileiro representados, respectivamente, por Zeballos e Quintino Bocaiúva, buscaram prontamente firmar um acordo bilateral para a definição de limites na litigiosa região de Misiones/Palmas.

Brasil e Argentina discutiam, desde o início da década de 1880, o direito sobre este território. A impossibilidade de se chegar a um acordo bilateral levou os dois países a firmarem um tratado, em 1888, estabelecendo o arbitramento como solução. Com o advento da República e sua tendência americanista, a resolução rápida das questões de limites tornou-se prioritária. Abandonando o que havia sido ajustado, Quintino Bocaiúva, novo ministro das Relações Exteriores, encontrou-se com seu respectivo argentino, Estanislao Zeballos, em Montevidéu, e buscou uma solução rápida e direta. Assentou um acordo que, de forma simplista, dividia o território entre as partes interessadas. A partilha do território disputado sem a necessidade de arbitragem levou, igualmente, a protestos violentos do Exército e da Marinha brasileiros e não foi ratificado pela maioria na Câmara dos Deputados, inaugurando uma nova fase nas negociações diplomáticas entre os dois países (PAREDES, 2011, p. 117). Segundo a perspectiva de José Paradiso (2005), essas desavenças quase levaram os dois países a um conflito armado, acentuaram as discórdias e fortaleceram a posição de confronto entre eles. Para o autor, o litígio da Argentina com o Chile adiou esse antagonismo, deslocando a atenção argentina para a fronteira andina.

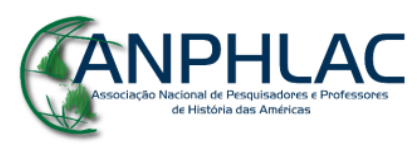


Na primeira década do século XX, a relação política entre Brasil e Argentina era regida, em grande medida, pelos grupos que estavam à frente do governo argentino. Pode parecer uma afirmação tendenciosa, mas que se sustenta quando observamos que a política externa do Brasil republicano entre os anos de 1902 e 1912 foi liderada, com ampla liberdade, pelo Barão do Rio Branco e seguiu uma linha condutora ao longo desse período. Dentre os preceitos empregados pelo chanceler brasileiro estava a consolidação de uma ideia de harmonia regional, revertendo o intervencionismo monárquico para a abstenção nos assuntos internos das nações vizinhas e de prestígio em relação à estabilidade dos governos instituídos, quaisquer que fossem eles. A Argentina, por sua vez, teve ao menos quatro ministros diferentes ao longo desses anos, e a tendência de cada um deles, e também de seus presidentes, determinava os ânimos das relações com o país vizinho. ${ }^{4}$

Situação sintomática que pode ser observada na comparação entre a gestão dos presidentes argentinos Julio Argentino Roca (1898-1904) e José Figueroa Alcorta (1906-1910). O general Roca estabeleceu com o Brasil uma relação de elevado nível de concórdia. Auxiliado por Manuel Gorostiaga, representante argentino no Rio de Janeiro, trocou visitas com o presidente Campos Sales e desestimulou, de maneira concreta, a ação das correntes antibrasileiras que agiam no interior da república platina. Roca, demonstrando intensa confiança na amizade entre as nações, recebeu de maneira natural os projetos de reconstrução da Marinha brasileira, em 1904, indicando boas oportunidades de compra para o Brasil, sobretudo de navios encomendados pelo Chile, mas que não seriam incorporados à Marinha do país andino.

Fausto e Devoto (2004, p. 231) explicam esse entendimento a partir do quadro das relações de tensão entre a Argentina e o Chile, em que o Brasil não tomou partido, adotando uma posição de neutralidade e afirmando sua disposição de atuar como intermediário em busca de um relacionamento pacífico. Acerca disso, Moniz Bandeira (1973) observa que a Argentina sempre temeu e evitou cair em uma situação que a deixasse política e militarmente comprimida entre o Brasil e o Chile, o que a levaria a lutar em duas frentes, em caso de guerra, com resultados catastróficos previsíveis.

\footnotetext{
${ }^{4}$ Outras referências importantes acerca desta questão são as obras de Luís Cláudio Villafañe G. Santos: $O$ Brasil entre a América e a Europa: o Império e o interamericanismo (do Congresso do Panamá à Conferência de Washington), publicada em 2004; O dia em que adiaram o Carnaval: política externa e a construção do Brasil, de 2010; O evangelho do Barão: Rio Branco e a identidade brasileira, de 2012.
}

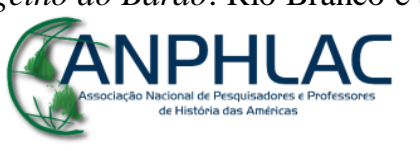


Assim, as relações de maior tensão ou de relativa aproximação entre a Argentina e o Chile tinham muito a ver com a postura mais ou menos amistosa do país andino para com o Brasil.

Contudo, o fim do mandato presidencial de Julio Roca e a retirada de Gorostiaga do Rio de Janeiro despertaram a dormente rivalidade. O vice-presidente, Figueroa Alcorta, assumiu a presidência no início de 1906 em virtude do falecimento do titular, Manuel Quintana, e designou Estanislao Zeballos, rival histórico de Rio Branco ${ }^{5}$, para chefiar, pela terceira vez, o Ministerio de Relaciones Exteriores y Culto. As relações diplomáticas argentinas no período em que Zeballos esteve à frente do Ministério das Relações Exteriores foram marcadas por disputas territoriais, rivalidades acadêmicas, antagonismos pessoais e político-partidários (PAREDES, 2011, p. 116-117). Sua atitude beligerante durante o avanço da década de 1900-1910 e o aumento das tensões internacionais, que acabaram desembocando na Primeira Guerra Mundial, contribuíram para que a Argentina vivesse sua versão própria e local da Paz Armada.

\section{O despertar das tensões}

A convulsão política e econômica dos primeiros anos da República brasileira, principalmente em relação às consequências da Revolta Federalista e da Revolta da Armada, prejudicou intensamente os meios e técnicas do Exército e da Marinha, notadamente desta última que vira sua frota tornar-se incapaz de cumprir suas obrigações mais básicas. Essa breve constatação confirma a inevitabilidade da reconstrução da armada brasileira. Diante disso, desenvolveu-se, entre os anos de 1904 e 1906, um programa naval que compreendia a compra de navios, cujos modelos eram

\footnotetext{
${ }^{5}$ A primeira desavença entre Zeballos e Rio Branco ocorreu em 1875, quando o enviado especial argentino no Rio de Janeiro, Carlos Tejedor, retornou à Argentina sem se despedir do Imperador. Na ocasião, o futuro Barão do Rio Branco defendeu, pelas páginas de $A$ Nação, que não houve "nenhuma ofensa internacional ao Brasil. Houve apenas uma gaucherie". Em Buenos Aires, os ânimos se exaltaram. Zeballos, através do jornal Nacional, respondeu ao jovem Paranhos, traduzindo erroneamente gaucherie como gauchada, afirmando: "Um dos diários mais importantes do Brasil qualificou de gaucherie a retirada do Sr. Tejedor. Este modo de se exprimir não é mais do que uma macacada de má lei. É melhor ser gaúcho do que macaco." Com a Questão de Misiones-Palmas, resolvida em 1895, havia se iniciado um novo período de embates entre os dois personagens que se estendeu até 1912, com a morte de Rio Branco.
}

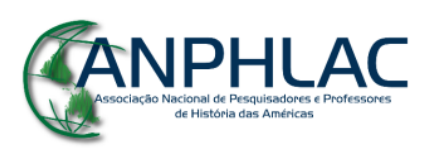


os das melhores esquadras da época, que recolocariam a Marinha brasileira entre as principais forças marítimas do continente.

A Argentina, por sua vez, estava condicionada pelos Pactos de Maio ${ }^{6}$, situação que contribuiu para que ecoassem no país denúncias acerca da insuficiência de sua defesa e da urgência na adoção de medidas para o reequipamento militar com vistas a impedir a supremacia naval do país vizinho. Zeballos transformou essa insatisfação em um dos motes de sua gestão e buscou com veemência a ampliação do poderio naval argentino para conter, pela força de imposição, qualquer tentativa de ingerência brasileira na Argentina, mas também nos demais países do Cone Sul. Instaurava, assim, um ambiente de corrida armamentista na América do Sul. A postura antibrasileira e acentuadamente belicista de Zeballos foi alimentada pela intensa aproximação entre o Brasil e os Estados Unidos, o que causava temores de uma tentativa de imposição de hegemonia regional, e, sobretudo, pela sanção da lei de armamentos navais no Brasil $^{7}$ em 1904 e, posteriormente, em 1906, que causou grande comoção em Buenos Aires.

Os antagonismos pessoais entre o Barão do Rio Branco e Estanislao Zeballos acabaram por se confundir com a oposição histórica das duas nações, o que elevou a tensão a tal ponto que a paz entre os países ficou ameaçada. Foram intensas as discussões entre os diplomatas e os representantes em Buenos Aires e no Rio de Janeiro sobre a questão naval, observando-se uma grande exaltação da opinião pública de ambos os lados. Essa ebulição foi incitada, em grande medida, pela utilização que os dois ministros faziam da imprensa para movimentar o cenário político. Zeballos tinha influência acentuada sobre periódicos que demonstravam constantemente sua postura antibrasileira, a exemplo do La Prensa, El Sarmiento e o La Razón, além da propriedade da Revista de Derecho, Historia y Letras, uma das principais vozes do ministro argentino. O Barão do Rio Branco, por sua vez, possuía uma atuação histórica na

\footnotetext{
6 Assinados em 1902 com o Chile, os Pactos de Maio determinavam a equivalência naval entre a Argentina e o Chile, o que a impedia de arregimentar seu programa naval.

${ }^{7}$ Em 1904, foi apresentado pelo ministro da Marinha, Júlio de Noronha, e defendido no Congresso pelo deputado Laurindo Pitta, um projeto de rearmamento naval que solicitava recursos para restaurar a Marinha Brasileira. Após longas discussões, foi aprovado o Decreto 1.296, de 14 de dezembro de 1904, que autorizava os recursos necessários para a implementação do projeto. Contudo, com a eleição presidencial de Afonso Pena em 1906, Júlio de Noronha foi substituído por Alexandrino de Alencar. Este buscou a anulação do Decreto 1.296 e apresentou um projeto que previa um orçamento ainda maior para o estabelecimento de uma esquadra mais poderosa, adquirindo o que havia de melhor e mais moderno na construção naval. Aprovada suas intenções, estabeleceu-se o Decreto 1.567 que aprovava os recursos para a nova proposta.
}

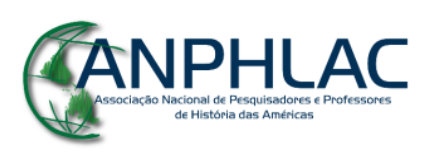


imprensa brasileira e que se tornara ainda mais sólida com sua atuação no Ministério das Relações Exteriores, escrevia nos principais jornais do Rio de Janeiro, a exemplo do Jornal do Commercio, O Paiz e A Notícia, além de influenciar diretamente nas pautas e na edição desses periódicos. Nesse sentido, optamos por analisar esses artigos, publicados tanto na imprensa brasileira como na argentina, no intuito de compreender como se desenrolou a crise armamentista que abalou as relações políticas dos dois países.

\section{Os debates na imprensa}

O temor por uma intervenção em meio a uma nova corrida imperialista, a completa falta de material para estruturar uma defesa litorânea e o fortalecimento político, econômico e militar da Argentina e Chile, levaram o Congresso brasileiro, em 1904, a votar e aprovar um novo Programa Naval, remodelado e amplificado em 1906. Segundo Bueno (2003, p. 183),

Fiéis ao espírito da época, as nações sul-americanas não escaparam, entre outras, da influência dos escritos do almirante norte-americano, Alfred T. Mahan, defensor da política de expansão naval e de grandes frotas. A vitória do Japão sobre a Rússia (1904-05), em guerra decidida nos mares, exerceu forte influência sobre os outros países interessados em modernizar suas armadas com a construção de encouraçados de grande porte.

Seguindo a perspectiva de Bueno, o espírito da época favoreceu o recrudescimento das antigas rivalidades entre Brasil e Argentina. O rearmamento transformou-se em um componente da disputa pelo prestígio e por uma suposta posição de liderança na América do Sul, contribuindo para criar um ambiente de elevada tensão, típico das corridas armamentistas. Entre os anos de 1904 e 1908, parte da imprensa argentina, comandada pelo influente Estanislao Zeballos, desenvolveu uma forte campanha a favor do rearmamento naval argentino, em contraposição ao que se fazia no Brasil. O La Prensa, um dos órgãos de imprensa mais exaltados desse debate, sugeria o rompimento do pacto de equivalência naval firmado entre Argentina e Chile, em 1902, apontando para a necessidade de formar uma grande armada:

(...) Prescindiendo por completo y con perfecta sinceridad de los designios del Brasil, argentinos e chilenos tienen que reconocer que su propósito de

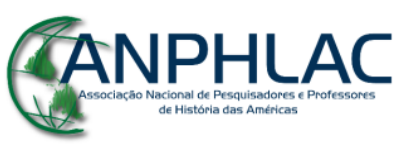

Revista Eletrônica da ANPHLAC, ISSN 1679-1061, №. 22, p. 182-201, Jan./Jun., 2017.

http://revista.anphlac.org.br 
conquistar el rango de primera potencia naval sudamericana da un argumento decisivo para romper el pacto de la equivalencia, devolviéndose la libertad plena para constituir su poder marítimo (...)

(...) La conciencia de la superioridad militar suele motivar veleidades de transcendencia en la vida de las naciones, de las vecinas sobre todo (...)

En consecuencia, la conservación de nuestro rango en el concierto de poder naval de Sud América es una garantía de la paz del Río de la Plata, contra cualquier veleidad, ofuscaciones o apasionamientos que pudieran producirse en el futuro. (LA PRENSA, 1904)

Outro ponto de preocupação do La Prensa residia na aproximação entre Brasil e Estados Unidos e a elevação mútua das representações desses países a Embaixadas. Para o periódico, essa ação, somada com o projeto naval brasileiro, apresentava graves riscos para a Argentina e os demais países da América do Sul.

\footnotetext{
¿Acaso ese importante detalle se relaciona con el plan diplomático que en hipótesis, venimos examinando?

E este punto disentimos abiertamente con el barón de Rio Branco. La idea resuena como un eco lejano de la edad monárquica del Brasil. El embajador representa la persona del soberano monarca. Si la Francia republicana conserva representantes de este título, si los Estados Unidos los han creado en Europa, es porque los embajadores ocupaban un rango superior al de los ministros plenipotenciarios ordinarios, y no consisten en su representación diplomática esté debajo de la de ninguna otra potencia.

¿Qué razones valederas pudiera invocar el Brasil para constituir embajadores en Washington? La sana razón nos vislumbra. (LA PRENSA, 1905)
}

Contudo, a preocupação do jornal La Prensa não se manifestava apenas em relação a esses dois fatores, mas, também, no que dizia respeito à exitosa política de prestígio internacional desenvolvida pelo chanceler brasileiro. Na década em que ficou à frente do ministério, o Barão do Rio Branco alcançou diversas vitórias, tais como (i) a consolidação das fronteiras, com considerável ganho territorial para o Brasil; (ii) o já citado estreitamento dos laços com os Estados Unidos, reforçado pela elevação das legações a Embaixadas; (iii) a criação do primeiro cardinalato da América Latina, que sediou a III Conferência Pan-Americana com a participação do Secretário de Estado norte-americano e (iv) a orientação, junto com Rui Barbosa, da defesa dos direitos das pequenas nações na III Conferência de Paz de Haia. Os sucessivos triunfos de Rio Branco, quando somados ao desenvolvimento do Projeto Naval, causavam temores na Argentina de uma possível tentativa de estabelecimento de hegemonia na América do Sul.

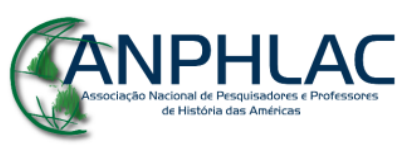


Reagindo às acusações do La Prensa, o Barão do Rio Branco também utilizou a imprensa brasileira como um instrumento para demarcar seu posicionamento político, por meio do qual rebatia as acusações tecidas pelos jornais argentinos. Publicou em $O$ Paiz um artigo anônimo com uma veemente resposta, entremeada por ironias, que refutava as críticas do jornal platino, além de apontar para o processo de reestruturação naval argentina, que se deu em meados de 1890, e para a reação sóbria e de respeito à soberania do país platino apresentada pelo governo brasileiro à época. Diante disso, chamou a atenção para as necessidades urgentes apresentadas pelo Brasil em sua reformulação naval:

(...) Nestes últimos 15 anos, causas sobejamente conhecidas determinaram o enfraquecimento do Exército e da Marinha de Guerra do Brasil. A revolta de uma parte da esquadra em 1893 fez nossa Marinha decair do primeiro para o terceiro plano. Enquanto isso acontecia, a Argentina criou rapidamente uma poderosa esquadra.

Não the pedimos contas por isso e não nos assustamos com tão grande aumento do seu poder naval. Agora, tratamos apenas de reconquistar em parte a posição perdida e devíamos esperar que a imprensa argentina imitasse a calma e a segurança que mostramos quando o seu país se armava. Temos um litoral imenso e um vasto sistema de comunicações fluviais a defender e a proteger. Não podemos prescindir de esquadra, e se a República Argentina entender que a sua não deve ser inferior à nossa não nos queixaremos ou gritaremos por isso. (RIO BRANCO, 1905)

Posteriormente, Rio Branco aludiu, de forma irônica, à possibilidade de uma hegemonia compartilhada no Atlântico sul-americano, enquanto o Chile, nação "amiga" tanto do Brasil quanto da Argentina, exerceria sua hegemonia no Pacífico:

Quanto à hegemonia ou preeminência na América do Sul, não a queremos disputar com a República Argentina.

No Pacífico, ela pertence inquestionavelmente aos nossos amigos do Chile, cuja esquadra nunca se há de reunir à outra para combater o Brasil, como imaginou há dias certo jornal de Buenos Aires. Na parte do Atlântico, teremos sempre prazer em dividir com a República Argentina, se assim se pode dizer, a parte de hegemonia que nos cabe. (RIO BRANCO, 1905)

Essa firme postura seguiu no artigo quando Rio Branco finalizou sua defesa evocando a soberania nacional brasileira para justificar o Projeto Naval, classificando o La Prensa como impertinente:

Não sabemos se a atitude de La Prensa corresponde a alguma corrente de opinião no seu país; no entanto, seja como for, é preciso reconhecer de modo categórico que essa atitude é positivamente impertinente.

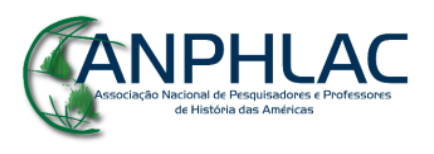

Revista Eletrônica da ANPHLAC, ISSN 1679-1061, №. 22, p. 182-201, Jan./Jun., 2017.

http://revista.anphlac.org.br 
Não agimos senão estritamente dentro das nossas faculdades de nação soberana, e qualquer que seja a preeminência que La Prensa reivindique para a República Argentina, forçoso será reconhecer que ela ainda não chegue ao extremo de nos ditar a lei dentro de nossa casa. (RIO BRANCO, 1905)

É imperativo indicar que Rio Branco demonstrava preocupações com o rearmamento brasileiro desde os anos finais do Império e engrossava as fileiras daqueles que apoiavam o projeto de reconstrução, mesmo que por questões de prestígio. Quando analisava os litígios fronteiriços com a Argentina já afirmava que "se os argentinos aproveitarem a ocasião teremos de passar por grandes vergonhas. Não temos esquadra, não temos torpedos, não temos Exército e os argentinos têm tudo isso." (RIO BRANCO apud BUENO, 2003, p. 220) Já como chanceler, voltou a marcar seu posicionamento em um discurso por ocasião de uma homenagem que lhe foi prestada pelo Exército Nacional, publicado em 1906 no Jornal do Commercio e apontou para a relação íntima entre a diplomacia e a guerra, sendo a segunda a continuação imediata da primeira. Afirmava que,

\footnotetext{
(...) o nosso amor à paz não é motivo para que permaneçamos no estado de fraqueza militar a que nos levaram as nossas discórdias civis e um período de agitações políticas que, devemos crer está encerrado para sempre.

(...) A grande extensão do nosso litoral e do nosso território interior, o exemplo de vizinhos que se armaram enquanto só cuidávamos da nossa política interior, impõe-nos o dever de reunir os elementos de defesa nacional de que precisamos (...). Carecemos de exército eficaz e de reservas numerosas, precisamos reconquistar, para a nossa marinha, a posição que antigamente ocupava.

Diplomata e soldado são sócios, são colaboradores que se prestam mútuo auxílio. Um expõe o direito e argumenta com ele em prol da comunidade; o outro bate-se para fazer vingar o direito agredido, respondendo à violência com violência. (RIO BRANCO, 2012, p. 155-156)
}

O posicionamento contundente de Rio Branco em seu discurso alarmou ainda mais o La Prensa, que passou a interpretar as intenções do diplomata como não pacíficas e a utilizá-las para convencer aqueles que ainda resistiam ao programa de rearmamento do país platino.

El Brasil, dice el barón de Río Branco, ostenta con orgullo una tradición diplomática de paz y hoy está en paz con sus vecinos y no vecinos, habiendo resuelto pacíficamente todas sus cuestiones internacionales; pero a pesar de todo, el Brasil debe amarse y recuperar su posición de primera potencia militar y naval que tuvo en otros tiempos. ¿Para qué? Para su propia seguridad interior y exterior, para la garantía de sus derechos "QUE A VECES SOLO LA FUERZA PUEDE DAR. (LA PRENSA, 1906)

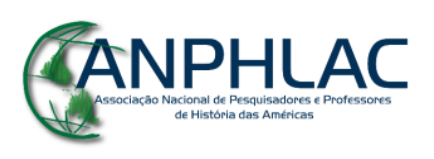

Revista Eletrônica da ANPHLAC, ISSN 1679-1061, №. 22, p. 182-201, Jan./Jun., 2017.

http://revista.anphlac.org.br 
Para Zeballos, a lei de armamentos brasileira tratava-se de uma questão de Estado e, por isso, afirmava compreender as motivações brasileiras - apresentadas pelo periódico carioca $O$ Paiz - segundo as quais o Brasil precisava de uma esquadra que satisfizesse suas aspirações legítimas e nobres. Conforme havia sido especulado por grande parte da imprensa brasileira, existia a expectativa de que Zeballos tomasse a iniciativa de uma campanha contrária à nova lei brasileira; contudo, em sua Revista de Derecho, Historia y Letras, fez questão de ressaltar a postura de aproximação e cordialidade sincera entre os dois países:

Pienso hoy, como en 1889 y en 1892 en el ministerio de relaciones exteriores, que hay conveniencias fundamentales, diplomáticas y económicas que aconsejan esta solidaridad de las dos naciones. Ellas tienen la responsabilidad del éxito de los anhelos de civilización y de libertad en Sur América. Ellas serán las grandes potencias continentales del hemisferio sur antes de cincuenta años (...). Soy, pues, amigo convencido y resuelto del Brasil. (ZEBALLOS, 1904b, p. 293)

Diante do exposto, Zeballos se voltou a buscar explicações para a compra de armamentos empreendida pelo Brasil e apontou as razões que considerava já serem conhecidas por muitos brasileiros e estrangeiros:

El Brasil necesita reorganizar su poder naval. Para el pueblo del Brasil esta reorganización es, además de necesaria, punto de amor propio nacional.

(...) Una nación como la vecina, cuyas costas marítimas corren sobre mil doscientas leguas, del Plata hasta las Guayanas, ofrece todo flanco marítimo descubierto al comercio de los países que dominan los mares.

(...) El Brasil siente necesidades supremas de seguridad y de vida externa e interna que no pueden ser satisfechas sino por medio de una marina de guerra eficiente. El Brasil ha sido, debe ser y será siempre una potencia naval. (ZEBALLOS, 1904b, p. 294)

Por meio destes trechos, entendemos que o ministro argentino concordou com a necessidade manifestada pelo Brasil de ampliar seus armamentos para proteção costeira e defesa territorial. Igualmente, ressaltou que a satisfação dessa necessidade deveria adotar uma medida razoável que, segundo Zeballos, escapava à observação do governo brasileiro. Considerou, portanto, como excessiva a quantidade de armamentos, já que, conforme afirmara o próprio Rio Branco, esta deveria responder apenas ao objetivo de defesa e conservação.

A apreensão de Estanislao Zeballos residia na possibilidade do Brasil constituir

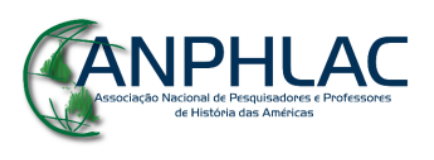

Revista Eletrônica da ANPHLAC, ISSN 1679-1061, №. 22, p. 182-201, Jan./Jun., 2017.

http://revista.anphlac.org.br 
uma força superior a todas as frotas sul-americanas reunidas, a qual poderia vir a ocupar, àquela época, o sétimo lugar entre as potências marítimas mundiais. Nesse sentido, argumentava que o Brasil se armava para superar a força naval argentina, bastante superior à sua e a mais importante da América do Sul. Ressaltou, contudo, que não concebia um propósito de ataque à Argentina, apesar de reconhecer a rivalidade alimentada pelos brasileiros. Em síntese, compreendeu que o Brasil não investia em armamentos com vistas a promover um ataque ao país "amigo", embora percebesse a necessidade de se precaver e superá-lo. Neste contexto, Zeballos passou a defender que a Argentina também se armasse, alegando as mesmas razões manifestadas inicialmente pelo Brasil.

Não obstante, defendia que a Argentina se posicionasse diante da postura adotada pelo Congresso brasileiro e considerava a existência de três caminhos diplomáticos possíveis de serem trilhados para a resolução do impasse. O primeiro, e preferido por Zeballos, consistia na negociação de um plano de desenvolvimento naval proporcional, econômico e racional que afastasse o perigo recíproco; o segundo residia em convidar o Chile, em nome da lealdade aos Pactos de Maio, a contribuir com a Argentina, realizando pressões sobre o Brasil e forçando seu governo a desistir de lançar a América do Sul em uma nova era armamentista. O terceiro, por sua vez, propunha que fosse denunciado o pacto argentino-chileno - baseado na limitação de armamentos - e que fosse adotado o mesmo critério estabelecido pelo Brasil e ratificado por sua imprensa: a necessidade de proteção.

Na Revista de Derecho, Historia y Letras, Zeballos advogava em favor de um "Destino Manifesto" argentino, noção associada à superação de obstáculos que se impunham à criação da nacionalidade. (ETCHEPAREBORDA, 1982, p. 52) Esta expressão foi empregada, pela primeira vez, naquele periódico, durante um discurso pronunciado por Zeballos no funeral cívico do General Bartolomé Mitre:

(...) los hombres del Plata entraran en acción con un verdadero "destino manifiesto". Dotados de una cultura más clásica que política, todo lo improvisaran: ideas de gobierno, soldados, generales y armamentos, y de triunfo en triunfo fundaron la independencia de Chile, del Uruguay, del Paraguay, de Bolivia, del Perú con sentimientos recíprocos e de civilización. (ZEBALLOS, 1906, p. 78)

\section{CANPHLAC}


Ainda com referência a esta ideia, em 1904, ao defender o desenvolvimento de uma política armamentista para a Argentina, Zeballos sustentou que:

\begin{abstract}
La vida de las Naciones modernas no es una Arcadia. Es de choques de intereses, de peligros y de sabias previsiones. Los países que por cobardía del espíritu público o por lirismo de sus estadistas hayan soñado que le es posible vivir fuera de la regla universal, es decir sin armamentos proporcionados, harían bien de abdicar de una vez su soberanía, ingresando como colonias inermes de las grandes potencias. Pero los pueblos viriles, por más mercantiles que sean - Estados Unidos, Alemania e Inglaterra lo enseñan deben aceptar simultáneamente cargas pecuniarias y la labor que la militarización de los tiempos les imponen, sin más limitaciones que las del criterio nacional, aconsejada por sus recursos y por sus necesidades. (ZEBALLOS, 1904b, p. 297-298)
\end{abstract}

Para Zeballos, a Argentina estava destinada a ser uma nação moderna com um povo viril, mas ele não era o único a professar a superioridade do país. José Ingenieros também o fazia, porém, a partir da superioridade da "raça argentina" explicada, por ele, com base em quatro fatores: a amplitude de seu território, a fertilidade de seu solo, seu clima temperado e sua raça branca. Esses fatores permitiriam que a Argentina superasse Brasil e Chile, seus adversários na região, consolidando, conforme defendia Ingenieros, a influência moral e material da Argentina na América do Sul. (INGENIEROS, 1956, p.120)

Com o acirramento dos ânimos, Rio Branco voltou a utilizar a imprensa para defender a posição brasileira. Dessa vez, o Jornal do Commercio foi o condutor das posições do diplomata que, com um artigo anônimo, contrapôs as práticas exaltadas e virulentas de um grupo reduzido da sociedade argentina à calma e ao bom senso demonstrados, segundo ele, pela maioria da população brasileira:

Há um esforço na República Argentina para que a campanha, que há muito tempo se faz contra o Brasil, se transforme em agitação. Para isso, um homem político se arroga o papel de representativo de uma velha sobrevivência, como é o preconceito dos ódios castelhanos e portugueses transportados para a América do Sul, e espalha o pânico da pátria em perigo. Não sabemos até que ponto as suas palavras são acreditadas pela maioria dos seus compatriotas, mas os seus adeptos, por diminutos que sejam, formam ainda assim a minoria que se move irrequieta por entre a massa da população argentina, criando sobretudo uma situação interna que é tempo de acabar.

Um povo é como uma criança, não pode permanecer sob a impressão de um espantalho. O desvario sobrevém fatalmente.

Em toda esta comédia, que um pouco mais de loucura pode mudar para tragédia, é singular a disposição dos espíritos brasileiros, calmos, indiferentes, quase risonhos, ante tanta fúria belicosa. Aqui não há atmosfera de guerra. (RIO BRANCO, 1908)

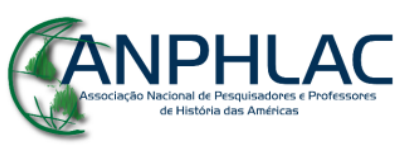

Revista Eletrônica da ANPHLAC, ISSN 1679-1061, №. 22, p. 182-201, Jan./Jun., 2017.

http://revista.anphlac.org.br 
Finaliza sua argumentação apontando para a orientação da política externa que já havia se afastado, há muitos anos, do intervencionismo e buscava projetar a imagem brasileira para o contexto internacional.

Há muito a nossa intervenção no Prata está terminada. O Brasil nada mais tem que fazer na vida interna das nações vizinhas. Está certo de que a liberdade e a independência internacional não sofrerão ali um desequilíbrio violento. O seu interesse político está em outra parte. É para um ciclo maior que ele é atraído. Desinteressando-se das rivalidades estéreis dos países sulamericanos, entretendo com esses Estados uma cordial simpatia, o Brasil entrou resolutamente na esfera das grandes amizades internacionais, a que tem direito pela aspiração de sua cultura, pelo prestígio de sua grandeza territorial e pela força de sua população. (RIO BRANCO, 1908)

Zeballos, entretanto, seguia no caminho oposto. Sua contundência nas acusações dos perigos oferecidos pelo rearmamento brasileiro permitiu que a campanha antibrasileira ganhasse ímpeto na Argentina o que, consequentemente, dava incentivos à sua exacerbação. O Chanceler argentino exaltava o patriotismo renascido na Argentina diante da complexa querela internacional:

\begin{abstract}
Algo muy argentino llena de orgullo a los espíritus que contemplan serenamente esta alta expresión del patriotismo nacional, y es la cultura, la circunspección, el respeto reinante en esas manifestaciones populares con relación a la acusa que las motiva; ninguna agresión, ningún descomedimiento por nadie; todos los entusiasmos para la patria, todos los anhelos de seguridad y de grandeza para ella. Esos pueblos no se conmueven sino para serví-la, para pedir a los poderes públicos, para exigirles que velen por ella, que la resguarden contra toda eventualidad, proveyéndola de los medios de defensa que necesitan su vida, su integridad y su honra. (ZEBALLOS, 1908, p. 302)
\end{abstract}

Nesse sentido, difundiu um plano que previa a exigência de o Brasil dividir seus navios e, advertia o governo argentino que, caso tal solução não fosse acordada, deveria ser preparada uma invasão ao Rio de Janeiro, com a mobilização da esquadra argentina e de 50.000 reservistas do exército. (DORATIOTO, 2000, p. 140) A proposta de divisão foi amplamente divulgada pelo diplomata argentino na Revista de Derecho Historia y

\title{
Letras:
}

Si el Brasil ama la paz, si es amigo de la República Argentina, si no se arma para imponérsele en la acción diplomática o militar, concluya en un día, en una hora, la negociación diplomática iniciada por mí, para dividir entre nuestros dos países amigos, su nueva escuadra. Cédanos de una vez un "dreadnought" y algunos otros cascos, ya que reconoció en mayo (1908)

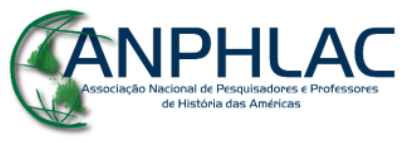

Revista Eletrônica da ANPHLAC, ISSN 1679-1061, №. 22, p. 182-201, Jan./Jun., 2017.

http://revista.anphlac.org.br 
cuando temían mi acción que era posible pactar la equivalencia naval sobre esa base. (ZEBALLOS, 1908b, p. 529)

Para infelicidade do diplomata argentino, suas intenções de intervenção no Rio de Janeiro foram transmitidas e publicadas pelo jornal La Nación, periódico que compunha uma frente oposicionista a Zeballos em seu próprio país. As reações no Brasil e no Uruguai foram imediatas. A pressão externa sobre o presidente Alcorta cresceu e tornou-se ainda mais acentuada pela ação da imprensa de oposição a Zeballos, representada por, além do já citado La Nación, El Diario e El Pais, os quais tinham um desempenho significativo sobre grande parcela da opinião pública argentina. Tornou-se insustentável a manutenção do chanceler que, em junho de 1908, acabou deixando o ministério.

A queda de Zeballos não deve ser considerada apenas como resultado de pressões externas, pois ele havia se indisposto, ao longo de sua carreira, com setores políticos argentinos e, também, de opinião pública, especialmente no tocante aos armamentos. Conforme demonstrou Etchepareborda (1982, p. 48-51), o próprio Zeballos reconheceu que sua saída do ministério esteve relacionada a intrigas de um círculo pequeno, uma espécie de ministério privado que cercava o presidente Alcorta. Sua renúncia deve ser compreendida, ainda, como uma alternativa a um conflito armado com o Brasil, isto é, como uma medida para evitar perturbações à paz estabelecida na região. Entretanto, isto não significou a interrupção de seus projetos de equilíbrio naval e, tampouco, pôs fim à tensão entre os dois maiores países sul-americanos que continuavam a alimentar as disputas pela hegemonia na região.

Ao deixar o cargo ministerial, Zeballos ainda causou incômodo ao Brasil, em especial a Rio Branco, ao publicar um telegrama cifrado enviado à Legação brasileira em Santiago. Esse documento passou obrigatoriamente pelo telégrafo argentino, onde foi interceptado e supostamente decodificado, revelando que as legações brasileiras em Montevidéu, Assunção, La Paz, Santiago do Chile, Lima e Washington, foram orientadas pelo diplomata brasileiro a fazer campanha contra a Argentina, acusando-a de pretender uma intervenção nos assuntos dos países mais fracos do continente. $\mathrm{O}$ episódio, conhecido como o "caso do telegrama $n^{\circ}$ 9", foi rapidamente desmentido por Rio Branco em um artigo, atribuído por ele a outro articulista, no Diário Oficial de 19 de setembro de 1908, no qual indicava que seria tarefa longa e desagradável a de

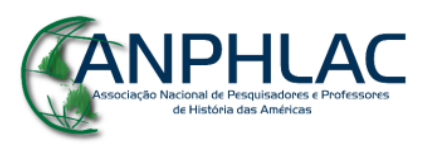

Revista Eletrônica da ANPHLAC, ISSN 1679-1061, №. 22, p. 182-201, Jan./Jun., 2017.

http://revista.anphlac.org.br 
retificar os numerosos enganos e erros de fato do que foi colocado por Zeballos, mas que tal reparação era necessária:

Tudo quanto afirmou o senhor doutor Zeballos nas linhas transcritas só pode ter por base a informação de algum homem da mais requintada má-fé. $\mathrm{O}$ atual ministro das Relações Exteriores do Brasil nunca dirigiu aos representantes desta Repúblicas no estrangeiro (nem em despacho oficial, pelo telégrafo ou pelo correio, nem em carta particular ou confidencial) instruções que tenham sequer a mais remota semelhança com as que lhe foram atribuídas. A ordem que o senhor doutor Zeballos apresenta entre aspas e que lhe disseram ter sido dirigida em 1908 a um dos agentes brasileiros no Pacífico é um documento absolutamente falso, no fundo e na forma. (RIO BRANCO, 1908)

Rio Branco tornou pública a chave utilizada para cifrar os telegramas brasileiros e o verdadeiro conteúdo da mensagem, comprovando assim a falsificação dos documentos oficiais efetuada por Zeballos. Impunha a seu adversário histórico uma última derrota e colocava sobre ele uma carga de descrença, apoiada e ampliada pelos setores políticos argentinos que se opunham a Zeballos. Com o político argentino afastado, ao menos oficialmente, das questões de política externa, as relações bilaterais entre Brasil e Argentina passaram gradualmente para um período de distensão, que se consolidou ao longo do governo de Roque Sáenz Peña, entre os anos de 1910 e 1914, acompanhado pelo término efetivo da corrida armamentista entre os dois países e consubstanciado na assinatura do Pacto do $\mathrm{ABC}^{8}$ em meados de 1915.

\section{Considerações finais}

Não buscamos negar aqui que tanto o Barão do Rio Branco quanto Estanislao Zeballos tiveram a pretensão de que seu país conquistasse uma posição de liderança na América do Sul. Contudo, ambos possuíam concepções diferentes em relação à conquista desse posto e de como o poderio militar se encaixaria nessas aspirações. $\mathrm{O}$ Chanceler brasileiro fundamentava sua política na busca por soluções diplomáticas para as situações que se apresentavam, mas, apesar de sua veia pacifista, não negava a importante função de sustentáculo que um poderio militar, com capacidade e

\footnotetext{
${ }^{8}$ Assinado por Argentina, Brasil e Chile, representava um pacto de não agressão, consulta e arbitragem entre os envolvidos. Além disso, pode ser interpretado como uma resposta à crescente influência estadunidense na região. Contudo, seu objetivo central era o estabelecimento de um equilíbrio entre as três maiores forças do Cone Sul.
}

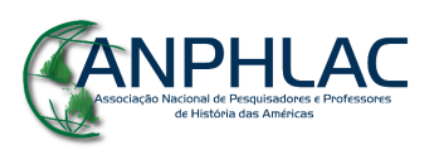

Revista Eletrônica da ANPHLAC, ISSN 1679-1061, №. 22, p. 182-201, Jan./Jun., 2017.

http://revista.anphlac.org.br 
credibilidade para dissuadir possíveis agressões, possuía no cenário das relações externas. O ministro argentino, por sua vez, permeado por um intenso alarmismo belicista, apoiava seus argumentos na existência de um "Destino Manifesto" argentino, com o qual se acreditava que o país estava fadado a ser uma nação moderna e com uma raça superior à de seus vizinhos e, dentro dessa aspiração, o fator bélico era elemento fundamental para proteger as fronteiras e expandir a cultura argentina para aqueles que dela precisassem.

O processo de reconstrução da Marinha brasileira surgia, assim, para opor essas duas concepções e movimentar os setores políticos dos dois países. Entretanto, esse debate não ficaria restrito a essa esfera oficial. Era de se esperar que ele chegasse também aos diferentes setores que constituíam a opinião pública brasileira e argentina e que essa se tornasse elemento importante na sustentação das posições apresentadas por cada um dos diplomatas. Para obter sucesso nesse aspecto, era imperativo a busca por enfraquecer e "desconstruir" a imagem e o discurso do adversário. Mais que isso, era necessário buscar não só o apoio interno, mas também conquistar alguma simpatia e apoio no outro país. A breve apresentação desses artigos, divulgados tanto na imprensa brasileira quanto na argentina, permite-nos observar uma interessante diferenciação na forma como os representantes dos dois países utilizaram as possibilidades discursivas da imprensa para colocar em prática tal objetivo.

O Barão do Rio Branco imprimiu à sua conduta diplomática o costumeiro caráter racional e pragmático, utilizando a imprensa, de forma anônima, para extravasar suas opiniões de forma mais veemente e incisiva, extrapolando, em alguns momentos, para a ironia. Essa atitude protegia sua imagem e lhe conferia grande popularidade frente ao contexto internacional, até mesmo no interior da sociedade argentina. Estanislao Zeballos, por sua vez, fixou, em diversos momentos, de forma atabalhoada, uma postura belicista e agressiva acerca da questão naval brasileira, contribuindo para a instabilidade nas relações entre os dois países. Sua ação na imprensa se dava de forma mais incisiva que a de Rio Branco, pois, ao assinar os artigos carregados de restrições ao Brasil e que marcavam a rivalidade com o Barão do Rio Branco, criou uma atmosfera oposicionista não apenas fora da Argentina, mas, também, dentro do país. Sua intempestividade dificultava a existência de simpatias pelas reivindicações

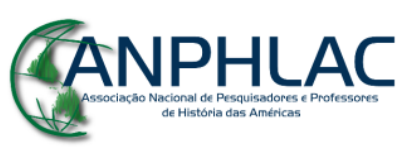


argentinas. Ademais, não podemos deixar de considerar que era uma batalha injusta, pois Zeballos gozava do apoio de uma parte restrita da sociedade argentina, enquanto Rio Branco, por seus constantes sucessos no ministério, era sustentado pela quase unanimidade da sociedade brasileira.

\section{Referências bibliográficas}

BANDEIRA, Moniz. A presença dos EUA no Brasil: dois séculos de história. Rio de janeiro: Civilização Brasileira, 1973.

BUENO, Clodoaldo. Política Externa da Primeira República: os anos de apogeu (de 1902 a 1918). São Paulo: Paz e Terra, 2003.

CERVO, Amado Luiz. Apresentação. In: BUENO, Clodoaldo. A República e sua Política Exterior (1889-1902). São Paulo: Editora da Unesp, 1995.

DORATIOTO, Francisco Fernando Monteoliva. A política platina do Barão do Rio Branco. Revista Brasileira de Política Internacional, vol. 2, n. 43, p. 130-149, 2000.

ETCHEPAREBORDA, Roberto. Zeballos y la política exterior argentina. Buenos Aires: Pleamar, 1982.

FAUSTO, Boris; DEVOTO, Fernando. Brasil e Argentina. Um ensaio de história comparada (1850-2002). São Paulo: Editora 34, 2004.

INGENIEROS, José. Sociología argentina. Buenos Aires: Editorial Tor, 1956.

LA PRENSA. Equivalencia naval. La Prensa, 10 de novembro de 1904.

. El Brasil en el continente. La Prensa, 15 de janeiro de 1905.

. Por la seguridad nacional. La Prensa, 13 de novembro de 1906.

MORGENFELD, Leandro. Vecinos en conflicto: Argentina y Estados Unidos en las conferencias pan-americanas (1880-1955). Buenos Aires: Ediciones Continente, 2011.

PARADISO, José. Um lugar no mundo. A Argentina e a busca de identidade internacional. Rio de Janeiro: Civilização Brasileira, 2005.

PAREDES, Rogelio. Estanislao Zeballos canciller: entre la diplomacia colonial y la guerra moderna (1878-1908). In: FERNANDÉZ, Sandra; NAVARRO, Fernando (Orgs.). Scribere est agere. Estanislao Zeballos en la vorágine de la modernidad argentina. Rosário: Quinta Pata \& Camino Ediciones, 2011.

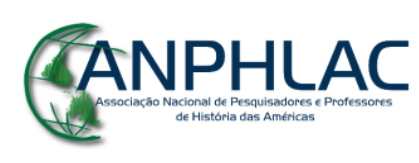


RIO BRANCO. Censuras Platinas. O Paiz, Rio de Janeiro, 18 de julho de 1905. Homenagem do Exército Nacional. Coleção Obras do Barão do Rio Branco: Discursos (IX). Rio de Janeiro: Funag, 2012, p. 151-157. . Brasil e Argentina. Jornal do Commercio, Rio de Janeiro, 26 de setembro de 1908.

Circular à Legação Brasileira. Diário Oficial, Rio de Janeiro, 19 de setembro de 1908.

SANTOS, Luís Cláudio Villafañe G. O Brasil entre a América e a Europa: o Império e o Interamericanismo (do Congresso do Panamá à Conferência de Washington). São Paulo: Editora Unesp, 2004.

. O dia em que adiaram o carnaval: política externa e a construção do Brasil. São Paulo: Editora Unesp, 2010.

. O evangelho do Barão: Rio Branco e a identidade brasileira. São Paulo: Editora Unesp, 2012.

ZEBALLOS, Estanislao. Los armamentos navales del Brasil. Revista de Derecho, Historia y Letras, Tomo XX, 1904a. . Los armamentos navales del Brasil. Revista de Derecho, Historia y Letras, tomo XX, $1904 \mathrm{~b}$.

. Mitre. Revista de Derecho, Historia y Letras, Tomo XXIV, 1906.

- Resurgimiento cívico. El alma argentina. Revista de Derecho, Historia y Letras, Tomo XXXI, 1908a.

. Diplomacia desarmada. Revista de Derecho, Historia y Letras, Tomo XXXI, 1908b.

\section{GANPHLAC}

